\title{
The Development and Application of the Art Resource of Zhuxian Town Wood New Year Painting in Design Course
}

\author{
Hongting Xiao \\ School of Art and Design \\ Huanghe Science and Technology College \\ Zhengzhou, China
}

\begin{abstract}
Although the collision and mutual tolerance of folk art and modern arts design is commonplace, in the aspect of teaching reform, the prominent change refers to constantly updating and developing the course content. This article mainly discusses the development and application of the art resources of Zhuxian Town Wood New Year Paintings and about how to expand the field of design specialty courses from depth and breadth; how to combine more specific and effectively with design specialty course. The author closely integrates the development situation of Henan higher education and the requirements of local economic construction, comprehensively researches and practices the teaching contents, course system, teaching method, teaching means of design. We should optimize education structure, create education pattern, promote the resources sharing, deepen educational reform, continually improve the teaching and education quality of design specialty, and infuse local features into the practical development of the art education in colleges and universities in our province. Besides, we need to build the system of art teaching course and take the path of characteristic development.
\end{abstract}

Keywords-Zhuxian Town Wood New Year Painting; design specialty; development, application

\section{INTRODUCTION}

The Zhuxian Town Wood New Year Painting has a long history and superb skills, unique local features and rustic folk style. Zhuxian Town Wood New Year Painting has values of many aspects such as high sociology, culturology, history, folklore, costume, aesthetic, etc. and it is a shining pearl of Chinese folk art. Mr. Luxun once gave high comments on it: "The Wood New Year Painting in Zhuxian town is very good. The graven line is not delicate carved but thick and strong, which is different from other places. These woodcuts are unadorned earthy without powder. The figures haven't coquetry. The color is very thick with local flavor. And it has the unique features of Wood New Year Painting in north China."

The development of the art resource of Zhuxian Town Wood New Year Painting in the course of major of art design and how to use it to inherit is an education base point with great potential value, which has the favorable conditions of sustainable development and utilization. We should give full play to its due role, which makes for cultivating students' creative learning ability and innovative consciousness. The reasonable development and utilization of the art resource of Zhuxian Town Wood New Year Painting has important value for the course development of design specialty.

\section{THE ABSORPTION AND REFERENCE FOR THE ART} FORMS AND CONTENT OF ZHUXIAN TOWN WOOD NEW YEAR PAINTING

The Zhuxian Town Wood New Year Painting integrates the teaching content of major of art design. In order to build course for major of art design with national features, perfect the development system of curriculum resources, except for writing the teaching material matching with it, we also need to explore the new integrating point between national art and modern design; the concrete implementation plans of teaching are as follows:

A. Theoretical research-aiming at learning theory, in depth knowing the history, development, art categories, artistic features, art appreciation and discussion of research of Zhuxian Town Wood New Year Painting.

The themes of Zhuxian Town Wood New Year Painting are extensive. It has rich content and deep implied meaning. Most of the themes and figures shaped by it are popular folk tales and legends, historical drama, historical novels and heroes adored and admired by people. The contents expressed by it come down in one continuous line with Chinese traditional culture and national religion, and most of them are themes such as wish, blessing, self-encouragement, enlightenment, happiness, longevity and celebration, etc. The themes can be mainly divided into two categories: one kind is the painting related to Gods, such as central scroll, strip screen, kitchen god, couplet, the Buddha, warehouse painting, the gods of heaven and earth; the other kind is door-god covering larger proportion. The two military officers on gategod pictures have different costumes, different shapes with more than 20 kinds of styles such as Bu Xia Bian, Ma Shang Bian, Baobian, Shudao, Pipao, etc. Besides, there are various kinds of civil and military door-gods. The civil door-gods 
include $\mathrm{Wu} \mathrm{Zi}$, Jiu Liandeng and Fukurokuju, etc. The military door-gods are the loyal officials, righteous person and heroes in Chinese opera. The doors of different people often paste door-gods of different contents. The doors of married people paste "the goddess sending children", "giving birth to lovely babies one after another", "San Niang Jiao"; the doors of middle-aged people paste "promotion in official post and salary increase", "continuous promotion step by step"; the doors of old people paste "longevity crane", "the god of longevity", etc.; the doors of children paste "five sons win titles", "Liu Hai making fun of the toad", etc. After liberation, artists create a batch of New Year painting with ages characteristics, such as the New Year works such as "the husband and wife learn to read", "the war to resist U.S. aggression and aid Korea, protect our homes and defend our country", etc.

Zhuxian Town Wood New Year Painting is native-born folk art and gradually forms the particular characteristics such as full composition, straightforward lines, exaggerating images, beautiful in colors through the creation of generations of artists. It inherits the traditional composition method in Han and Tang dynasties. The composition is full and compact, symmetrical and ingenious, which absorbs all kinds of composition technique such as fresco, painting, wood carving, tile carving, etc. in Han and Tang dynasties. The lines are bold and unconstrained. Yin and Yang have striking contrast. Especially in the grains of clothes in the pictures of gods, its manifestation is more obvious with a lot of local flavor and it has simple, thick and solid, robust, bold and unconstrained styles of northern ethnic groups. The shape of characters is not according to the convention, and doesn't pursue the proportion. While it uses exaggeration to highlight the heads of figures. We can know the personal character when we see the face of the figure. It devotes particular care to the use of colors. It uses principal raw materials such as pine soot, minium, sophora flower bud, verdigris, mallow seed and gold foil, etc. to refine and confect all kinds of pigments. The printed New Year paintings have dense color, cannot be damaged by worms, don't lose color, don't run color and they are suitable for mounting and collection. The paintings can keep bright forever, and like new after being stored for a long time.

\section{B. On-the-spot investigation and research-going deep} into Zhuxian town to investigate and using inspection methods such as collection, shoot, picture recording, etc.

It can help people to deepen the understanding for traditional culture and national art. After the founding of new China, the ancient folk art is inherited and developed. Zhuxian Town Wood New Year Painting Association is established and it creates new works of New Year painting with national features and spirit of the time, which form workshop and sales and the wholesale market with modern scale. The products not only have traditional manual color process but also have offset printing. Thereby, the artistic treasure achieves rich achievements in the garden of many flowers.

Zhuxian Town Wood New Year Painting was selected in the first batch of national intangible cultural heritage list in
2006. According to the survey, the original New Year painting created by generations of artists has about more than 500 kinds. The 210 sets of the surviving ancient version of history have a total of 1200 pieces, version of the Ming dynasty 2 pieces, version of the Qing dynasty 23 pieces, version of the republic of China 28 pieces. There are many New Year paintings are treasured in famous museums at home and abroad. It is praised as the national treasure of China by international experts and scholars.

Furthermore, Zhuxian Town Wood New Year Painting also takes part in large-scale expo such as the World Leisure Expo, Shenzhen World International Cultural and Creative Industry Expo, etc. and it repeatedly win the gold medal. On the eve of the Spring Festival, the everlasting traveling merchants come to Zhuxian town to wholesale offset printing New Year paintings. The number of business users working on the offset printing New Year paintings is more than 20. The whole town prints and sells manual wood New Year paintings of about 5 million copies every year. The output value brought by wood New Year painting and offset printing New Year painting has reached as much as 75 million yuan. The varieties of New Year painting has precious ancient version of Ming and Qing dynasties traditional New Year paintings with limited printing, as well as the modern New Year paintings loved by people which inherit the tradition, imitate the modern. Its content and form has higher value of art appreciation and historical data collection. It is a treasure for folk New Year painting art lovers at home and abroad and professionals to research and collect. And it is deeply loved by guests from home and abroad and the experts and scholars.

\section{Experience and Exploration-Zhuxian Town Wood New Year Painting provides the opportunity for students of art major to experience and feel the process of technology.}

Modern design requires the technology to improve continuously, which has higher requirements for design. When the design and technology have contradictions, the technology must comply with the design. Designers also improve this understanding. Each production link must conform to the overall design. And designers have transferred from feeling passively to guiding actively. Because of the characteristic of major of art design, they should be responsible for guiding industrial projects. The production of Zhuxian Town Wood New Year Painting adopts printing techniques such as the ancient wood sculpture and the combination of watermark and color process. The production divides into several processes such as painting, sculpture, printing and mounting, etc. Every process is extremely fine and accurate and it is the most advanced color printing in the world at that time.

The engraving process divides into engraving line version and color plates. The material is fine pear wood board with thickness of 2 inch and a half, smearing plant oil on the board surface for 3 or 4 times, after drying naturally, using boiling water to wash. Then people use scraper to scrape the oil spill on the surface, paste the rough sketch with black lines on the pear wood board, use ways of cutting of 
"cutting", "follow", "prop up" and "scrape" to scribe lines. The lines above must wide and the lines below must narrow, bold and fluent, being scribed at one sketch. The color plate of New Year painting is named "baking copy", designing colors for carved line version and dividing into blocks, one block with one color. The carve workers grave according to the color separation of line version. Middle court and Ermao need 5 or 6 blocks of color plates and Damao needs 7 to 8 blocks of color plates. The block carving is very crucial. A piece of good block carving should maintain the style of writing and force of traditional line-drawing, and reflect the wood aroma of wood New Year painting. The block carving itself is an independent work of art.

Color blending and modulation. Zhuxian Town Wood New Year Painting adopts homemade mineral and plant pigments, and uses materials of pine soot, minium, sophora flower bud, verdigris, mallow seed and gold foil and uses multiple color manufacturing process of fry, stew and filter to refine carefully, adding alum and lime to green and purple color. The green and purple color ferments, making the color steady and easy on eyes and have lasting appeal. The printed New Year paintings have dense color, cannot be damaged by worms, don't lose color, don't run color and they are suitable for mounting. The paintings can keep bright forever, and like new after being stored for a long time.

When printing, people add residual tea water to the color to make the New Year painting non-sticky after drying. After the republic of China, the pigments gradually adopt chemical dyestuff.

In old days, the printed paper of New Year painting adopts local soil paper and feather edge paper. Now it uses China's traditional raw rice paper to print. For the print of New Year painting, in general, 200 pieces of paper is one "block". When printing, people clamp the papers on the bamboo clip according to "block". When the papers are firmly clamped, they insert "canal pin" in one side and put another side into grey brick slot, fold the papers into the shape of " $\mathrm{S}$ " to make it convenient for printing.

D. Integration and utilization-for the art structure of Zhuxian Town Wood New Year Painting, arrange, analyze and extract, compact the object, determine the final design plan according to area, location and shape, mainly focus on the training of creative thinking.

Zhuxian Town Wood New Year Painting the embodiment of specific period, specific regional culture and it is the visual reflection of the specific spiritual connotation of Zhuxian Town and it has unique artistic charm. In order to make folk art extend and develop in modern design and create new national form, we should take its "shape" and continue its "meaning" and then pass its "spirit" on the basis of understanding. Therefore, we anew know and create the modeling, color, way of thinking, aesthetic pursuit and value embodiment, which is deepening and promotion, profound analysis for modern artistic designing and cultural connotation from the folk reproducibility. It is essential for current artistic designing.

\section{THE INHERITANCE AND DEVELOPMENT OF ART RESOURCES OF ZHUXIAN TOWN WOOD NEW YEAR PAINTING}

At present, the shortage of professionals to make Zhuxian Town Wood New Year Painting, comparatively simple training mode and young people's unwillingness to learn lead to the fact that there are no successors for wood New Year painting, which have the relations with the problems of whether the skill can be inherited and whether the industry can sustainable develop. Zhuxian Town Wood New Year Painting becomes the resource that people have faith in and it becomes a popular resource among all the people. The design specialty in universities has many talents. Teachers' teaching concept is very new and they can put talents cultivation into practice. Professional teachers can take special policies and measures starting from the development of national culture to make a batch of artistic competitive products full of the characteristics of Zhuxian Town New Year Painting and develop some new varieties at the same time. Besides, we talk about gifts and tourist souvenirs and the products that students turn design ideal into reality. Except for theoretical research, teachers also can strengthen the excavation of the technical skills of Zhuxian Town New Year Painting and build systematic and scientific theoretical system. Teachers also can transfer the declaration of science and technology project of works after implementation into scientific and technological achievement. As teachers "teaching benefits teachers as well as students", in this course and teaching practice, their understanding gradually becomes clear and definite: as excellent designers in China's future, they cannot be short of the basic quality and technical training of the national artistic expression and cultural and aesthetic psychology. Therefore, cooperating with major of art design in universities makes up the shortage of industrial talents and realizes resources integration.

\section{DEVELOPMENT AND UTILIZATION OF ART RESOURCES OF ZHUXIAN TOWN WOOD NEW YEAR PAINTING}

At first, we should give play to the traditional handicraft of wood New Year painting and its material characteristics, continue to intensify our own advantages, develop traditional elements and make better artistic competitive products. Some people want to collect. Some folk handicrafts have become collection and the investment direction of people. Therefore, traditional things need excavating. But there are fashion crowd. The price orientation is middle and low in accordance with the purchasing power of age location. Moreover, the market space is very large. So some new varieties need to be developed, such as gifts, decorations to beautify the body, exhibiting decorations and plaything, tourist souvenir, etc. If Zhuxian Town wants to develop, it must develop tourism and we must occupy this market. It should be associated with interior decoration and the environment design to make some indoor and outdoor decorations. This batch of products is suitable for mass production and can meet the requirements of modern industry, can develop on the technology and constantly develop and integrate new material, new technology and new processing means, because the requirement of the current 
market is diversified. For example, we can use some abstract products with modern style, so the coverage of the shop is wider. Under the lead of teachers, students in major of art design completely have the ability to develop new products, adapt to the requirements of society and develop the connotation of Zhuxian Town New Year Painting.

\section{The Meaning of the Integration Between the ART RESOURCES OF ZHUXIAN TOWN WOOD NEW YEAR PAINTING AND THE EDUCATION OF DESIGN CLASS IN UNIVERSITIES}

\section{A. Promote the "cultural self-consciousness" of college students, cultivate students' consciousness of national cultural inheritance and improve the literary accomplishment.}

Design specialty is different from other disciplines. It has the responsibility to inherit the culture while imparting knowledge and developing skills. In 2001, the 16th national congress report of Chinese Communist Party clearly put forward the Party's educational policy: "education must serve the socialist modernization and the people. It must combine with productive labor and social practice and cultivate socialist builders and successors with all-round development of morality, intelligence, physique and aesthetic. Design specialty is the combination of technology, fine arts and technology. At present, there are less learning curriculums of design specialty in the aspects of material and craft production and they don't conform to the reality. Some subject design of students still stays on the design drawing period because of the limited condition. They cannot grasp the performance and essential characteristics of the arts and crafts material of design works through practice. Combining the education of design specialty and practice, not only the schools save equipment funds and the place input of craft production, but also students have opportunities to enhance the perceptual knowledge of craft material. In order to cultivate high level design talents with innovation consciousness, the design course must closely keep up with the pace of the times and actively discuss the innovative teaching resources with constant integration on the basis of insisting knowledge, ability and quality. The art resources of Zhuxian Town Wood New Year Painting provide a platform for major of art design. Students have many creative passion and thoughts but they lack the platform which can make thoughts become products. The educational goal, object and way of the design specialty course have particularity. It must cultivate art design talents and has the responsibility of excavating, arranging, protecting and inheriting national culture and art as well. Introducing corresponding content to art education course can not only perfect the function of art education, and make students realize the value of national art, know the cultural connotation contained in national art, but also increase the attraction and vitality of art education, make students receive education under the active and selfconscious state and truly build up students' humanistic spirit cultural quality.

\section{B. Promoting higher education to make full use of folk art resources helps the course system of design specialty to develop in a larger direction.}

In the course teaching of major of art design, teachers cannot only use simple explanation and appreciating way, they should vigorously strengthen the internship and practical training of art education course. The internship and practical training of art education course includes two aspects: first, enhance the interactivity of teaching, make students do it themselves or participate in, arouse the enthusiasm and initiative of their learning and then improve the efficiency of education and teaching; second, create the atmosphere of learning, use real or simulative living environment and art environment to mobilize students' emotional experience, motivate their enthusiasm and creativity and enrich the form and content of art education course teaching, establish practice base in Zhuxian Town New Year Painting Association to provide practice place for teachers and students. The art resources of beautiful and unique Zhuxian Town Wood New Year Painting are very rich, which can make the course content of art design diversified and vivid. And then stimulate students' interests, arouse students' art perception of external things, guide and cultivate students to feel the unique emotional experience, encourage students to express ideas confidently, develop their creativity, and improve their practical ability and design level. Besides, through teaching, make students understand and master relevant content of Zhuxian Town Wood New Year Painting such as source, background, artistic characteristics and manufacture craft, compare with hometown folk art characteristics from the aspects of style, color and composition, broaden horizon, think and sublimate the understanding for Chinese folk art, the understanding and research and development of folk art, arouse students' creative passion for modern design. In addition, teachers should enhance students' cognition and protection for National Intangible Cultural Heritage to make the endangered national essence be inherited, better combine the technology of folk characteristics with modern art in today's society to design more and better artistic works to serve the society.

\section{CONCLUSION}

Institutions of higher learning are the base to cultivate talents and also the important canal to inherit and develop excellent ethnic heritage. Integrating art form, cultural connotation and aesthetic experience of excellent folk art and various technologies into contemporary higher education of design is more beneficial to promoting the development of painting, sculpture and folk art, folk culture in new period, makes design class design maintain the source of Chinese folk culture and make the intersection of primary of folk fine arts and ethnology, folklore, cultural ecology become more obvious, which has important reference value for the development of modern Chinese art. 


\section{REFERENCES}

[1] Liu Tiehua; Introduction of the survey of Zhuxian Town Wood New Year Painting [J]; Journal of Henan University (social science edition); the 1st issue in 1980

[2] Wang Shucun; About the Folk New Year Painting [J]; Art Research; the 2nd issue in 1980

[3] Feng Xiangyi; The Characteristic of New Year Painting and Getting Rid of the Stale and Bring Forth the Fresh [J]; Art Research; the 2nd issue in 1980

[4] Wang Shucun; Summary of Fujian Traditional New Year Painting Survey [J]; Fine Arts; the 4th issue in 1980

[5] Luo Shubao; The Earliest Wood New Year Painting Existing in China [N]; China Packaging News; 2000

[6] Liu Xianqin; Kaifeng Must Implement the Strategy of Grand Tour [N]; Guangming Daily; 2000

[7] Chen Zhijuan; Past, Present and Development Conception of Kaifeng Wood New Year Painting [D]; Capital Normal University; 2006 